\title{
O ANUÁRIO DE LITERATURA E SEU BAÚ DE MEMÓRIAS: DO PERIÓDICO ANUAL À REVISTA ELETRÔNICA SEMESTRAL
}

\author{
Carolina C. Lima Dittrich ${ }^{*}$ \\ Fernanda Müller ${ }^{* *}$ \\ Rafael Z. Copetti ${ }^{* * *}$ \\ Universidade Federal de Santa Catarina
}

Em uma tarde quente e abafada do mês de março de 2008, o professor Stélio Furlan se dirigia apressado a uma sala do Bloco B do Centro de Comunicação e Expressão da UFSC para mais uma reunião do Anuário de Literatura. Mal sabia ele que aquela não seria "mais uma" reunião, mas um divisor de águas no trabalho até então desenvolvido pelo periódico. Naquele momento, Stélio buscava formar uma equipe mais coesa para dar continuidade à publicação, tendo em vista que das equipes editoriais anteriores só havia restado Rafael Zamperetti Copetti, também recém incorporado ao quadro.

Embora a chamada fosse extensiva aos antigos editores, compareceram na reunião daquela tarde, além de Rafael, apenas Carolina Cerqueira Lima Dittrich, a

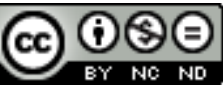

Esta obra está licenciada sob uma Licença Creative Commons.

\footnotetext{
* Mestre em Teoria Literária pela UFSC, Bacharel em Letras e Literatura Francesa, experiência na área de Letras, com ênfase em Língua Francesa.

** Doutora (2011) e Mestre (2006) em Literatura pela Universidade Federal de Santa Catarina, licenciada em Letras Português, Inglês e Literaturas correspondentes pela Universidade Federal de Mato Grosso do Sul (2003). Atualmente é professora de Língua Portuguesa do Colégio de Aplicação - UFSC *** Doutor em Teoria Literária pela Universidade Federal de Santa Catarina [2012], com tese sobre os manifestos do Futurismo Italiano. Possui graduação em Letras [2001] e Mestrado [2005] em Teoria Literária pela mesma instituição. Atualmente realiza estágio de pós-doutoramento junto ao Programa de Pós-Graduação em Estudos da Tradução da UFSC, com pesquisa sobre os manifestos do Futurismo Italiano.
} 
convite do próprio Stélio, e Fernanda Müller, que havia se inteirado da revista junto a Rafael. Três estudantes da Pós-Graduação em Literatura e um professor do Curso de Letras, portanto, que formariam o novo time do Anuário e tocariam a revista por três anos consecutivos até que novos editores integrassem o quadro hoje. Atuaram como editor-chefe da revista nesse momento Fernanda Müller [março/2008 fevereiro/2009], Carolina Dittrich [março/2009 - fevereiro/2010] e Rafael Zamperetti Copetti [março/2010 - fevereiro/2011], sempre contando com Stélio Furlan como professor responsável e conselheiro atento.

O ano de 2008 seria marcante. Para a história da revista, que passou por significativas mudanças editoriais, alterando a periodicidade, o formato, a plataforma, expandindo o conselho consultivo e por aí foi. E para os editores, que aprenderam o que é publicar um periódico vendo-se às voltas com um. Por isso, quando enfatizamos que se tratou de um ano "marcante" não nos referimos apenas à criação de um novo grupo que assumiu os riscos de comandar uma revista até então sem uma linha editorial muito clara, mas a uma discussão mais ampla que incluía pensar o papel do Anuário, quais concepções norteavam o nosso trabalho e o que pretendíamos para o periódico dali em diante. Tais desafios nos aproximaram muito, e os inúmeros encontros e incontáveis e-mails trocados resultaram em fortes laços profissionais e afetivos, que ultrapassaram esse período.

Resgatando a história do Anuário, desde 1993, ou seja, há 19 anos, quando foi concebida pelo professor Walter Carlos Costa, contando com o apoio e editoração do professor Alckmar Luiz dos Santos e com a colaboração das discentes Maria José Angeli de Paula e Daisi Vogel. Até 2007, a revista, que possuía periodicidade anual, tinha como objetivo a publicação de artigos dos alunos e dos professores do Curso de Pós-Graduação em Literatura da UFSC. Tendo em vista as demandas e orientações oficiais, sentimos a necessidade de abrir, a partir de 2008, à colaboração discente de outros programas de pós-graduação brasileiros. Como pretendíamos migrar para a plataforma digital, o tamanho da publicação e os custos em decorrência do número de páginas tornavam-se desprezíveis, o que nos fez regular, a partir dali, o número de textos e a seleção dos mesmos pelo mérito, não pela instituição da qual seu autor era proveniente. Pela mesma razão a revista passou a ter periodicidade semestral, o que implicava mais trabalho para a equipe editorial, mas não custos e toda a lentidão que faz parte da aprovação e impressão de exemplares no papel. 
Outra importante mudança sofrida pela revista diz respeito ao seu formato: a edição de 2007 já havia sido a primeira a ser disponibilizada inteiramente em formato eletrônico, mas o fora em um site criado especificamente para a revista. A edição de 2007 merece ainda ser destacada por contar com uma homenagem ao artista plástico catarinense Rodigo de Haro, que produziu uma gravura especialmente para ilustrar a capa daquele número. Um artista importante para Santa Catarina, mas especialmente ligado à nossa Universidade, tendo em vista que De Haro é, também, autor do mosaico que adorna o acesso frontal do prédio da reitoria da UFSC, obra de arte que faz parte do patrimônio cultural remetendo à identidade de nossa instituição.

Logo nas primeiras reuniões da equipe editorial em 2008, sem saber se deveríamos prosseguir publicando em site específico, voltar à impressão ou aderir a algum tipo de sistema de publicação, tomamos contato com o SEER - Sistema Eletrônico de Editoração de Revistas, em implantação na UFSC naquele momento sob a tutela do Departamento de Ciência da Informação, coordenado pela Profa. Dra. Ursula Blatmann e sua equipe. A plataforma seria lançada no II Simpósio Brasileiro de Comunicação Científica, do qual a equipe do Anuário participou representada por Fernanda Müller.

A adoção da plataforma SEER exigiu que os editores frequentassem um curso de capacitação específico, promovido pelo próprio Departamento de Ciência da Informação. Tal curso foi fundamental para oferecer suporte não só a nós, editores do Anuário, mas a todos os editores de periódicos da UFSC que até então publicavam em versão impressa e se viam pressionados a aderir ao formato eletrônico. Quando da migração integral do Anuário para a plataforma de periódicos da UFSC, esta contava com apenas 12 periódicos totalmente digitalizados e mais de 32 ainda em processo de migração. Mais barato e de alcance infinitamente superior, a utilização do sistema SEER permitia disponibilizar nossos textos a leitores distantes. Um claro exemplo disso é o registro de acesso à revista de países europeus, africanos e latino-americanos: há mais de 100 países listados com visitas regulares às nossas páginas.

Com a publicação do seu $13^{\circ}$ número, em 2008, a revista passou a utilizar o sistema eletrônico da UFSC, mas não bastava seguir as normas do SEER para publicar dali em diante por esse meio. Assumimos o compromisso de disponibilizar todos os números anteriores da revista. Para tanto, como não havia mais as matrizes das publicações daquela primeira década e meia de Anuário, foi necessário recorrer às prateleiras do Programa de Pós-Graduação em Literatura para obter exemplares dos 
volumes até então publicados. De posse desse material, recortamos na Imprensa Universitária da UFSC as lombadas de um exemplar de cada volume da revista, os levamos até o Departamento de Ciência da Informação e lá os escaneamos folha por folha.

Escanear não era o fim do processo, mas uma das etapas dele, já que precisávamos converter para $\mathrm{PDF} / \mathrm{A}$ cada expediente, artigo, ensaio, texto de natureza literária ou entrevista publicada. Fragmentados e convertidos em arquivo digital próprio, cada texto necessitou, ainda, que fossem inseridos os seus metadados, informações que facilitam a busca pelas palavras-chave na rede. Abrir esse baú de memórias foi o nosso compromisso para aumentar a periodicidade e expandir a visibilidade entre os leitores. Realizamos, pois, a migração dos 11 volumes anteriores do Anuário de literatura, o que acarretou num total de 140 artigos em mais de 2.000 páginas, escaneadas e cadastradas uma a uma pelos seus quatro editores.

De lá para cá, a revista manteve seu compromisso de publicar semestralmente textos de cursos de pós-graduação nacionais avaliados com rigor por um corpo de pareceristas de renomadas universidades nacionais e internacionais. Sofreu, ainda, uma série de alterações em seu layout a fim de conferir uma identidade própria ao Anuário, projeto que passou a incluir, aliás, a elaboração das capas com imagens de obras de arte de artistas locais. Embora as edições não fossem temáticas, mas contemplassem temas variados, houve espaço desde a migração para dialogar com o Futurismo Italiano (v.13, n.1, 2008), a Arte Naif (v.13, n.2, 2008), a poesia e a música rimbaudiana (v.14, n.1, 2009), o Homo academicus, de Pierre Bourdieu (v.14, n.2, 2009), a obra de JeanLuc Nancy (v.15, n.1, 2010), a mescla artística simbolizada pelo galo filatélico do catarinense Meyer Filho (v.15, n.2, 2010), o movimento e o dinamismo do circo, do carnaval, da arte e da vida da reconhecida artista plástica brasileira Eli Heil, (v.16, n.1, 2011), os modos, as formas e os sentidos de derivas via arte do conterrâneo Hassis (v.16, n.2, 2011), até o volume anterior a este, costurando imaginário e imagem, literatura e cinema, por meio do dragão da artista catarinense por opção, Nadir Ferrari (v.17, n.1, 2012).

Atualmente, a revista Anuário de Literatura conta com os editores Jair Zandoná, Andrea Figueiredo Leão Grants, Tanay Gonçalves Notargiacomo, Gizelle Kaminski Corso e Stélio Furlan, sendo que estes dois últimos atuam respectivamente como editora-chefe e professor responsável pela publicação. A atual equipe editorial, à exceção do Prof. Dr. Stélio, ingressou na editoria no segundo semestre de 2010, 
período em que os antigos editores passaram gradativamente a se desvincular do periódico por motivos acadêmicos: a conclusão de nossos doutorados e mestrado em literatura na PGL. O segundo semestre de 2010 marcou, assim, o período de transição para que a atual equipe assumisse a revista já no ano de 2011.

Nós, da antiga equipe editorial, convidados pelo professor Stélio e pelos atuais editores da revista para rememorar nesses vinte anos de publicação um pouco da história do Anuário, só temos a agradecer. Agradecer pela confiança em nós depositada para fazer voltar à circulação uma revista tão importante para a PósGraduação na qual obtivemos nossos títulos e para seus alunos, bem como pela oportunidade de aprender tanto ao longo do processo de migração dos números impressos para o portal de periódicos e da editoração dos demais volumes. Em um misto de saudade, carinho e orgulho, registramos nossos cumprimentos:

Salve Anuário! Parabéns pelo conceito B2, conferido pela CAPES após muita dedicação, e vida longa a seus textos, que não mais se perderão em gavetas ou prateleiras, mas que continuem a ganhar o mundo acadêmico!

Outubro de 2012.

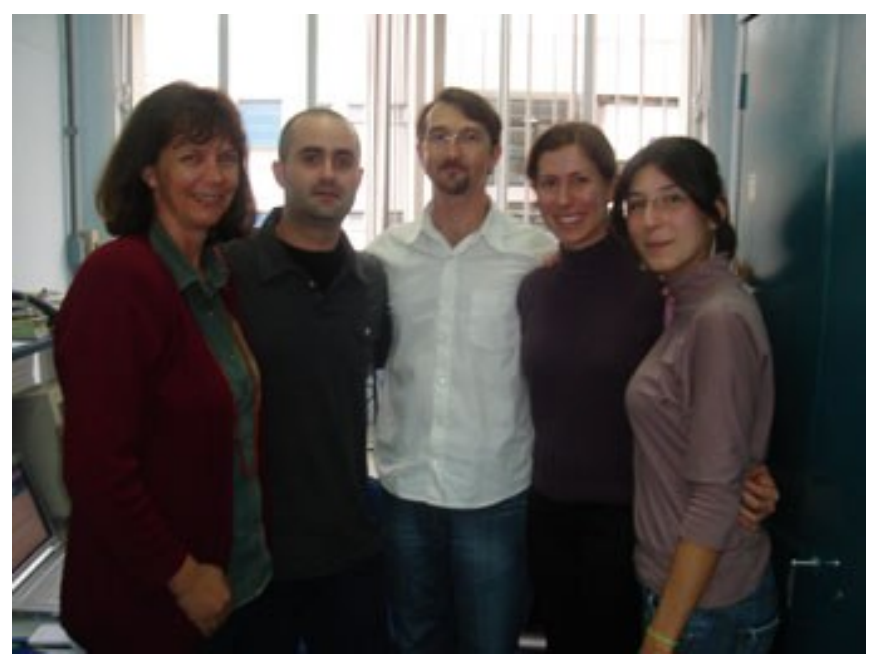

Foto: Dep. de Ciência da Informação, abr. 2008. Equipe editorial do Anuário de Literatura, editoreschefe de 2008-2010. Da esquerda para a direita: Profa. Dra. Úrsula Blatmann (Dep. Ciência da Informação), Prof. Dr. Rafael Zamperetti Copetti, Prof. Dr. Stélio Furlan, Profa. Dra. Fernanda Müller e Profa. Msc. Carolina Cerqueira Lima Dittrich.

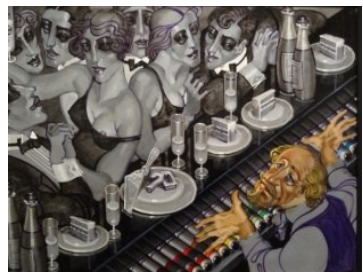

